\title{
Dual Delayed-Release Dexlansoprazole for Healing and Maintenance of Healed Erosive Esophagitis: A Safety Study in Adolescents
}

\author{
David Gremse ${ }^{1} \cdot$ Benjamin D. Gold ${ }^{2} \cdot$ Betsy Pilmer $^{3} \cdot$ Barbara Hunt $^{3} \cdot$ Bartosz Korczowski $^{4} \cdot$ Maria Claudia Perez $^{3}$
}

Received: 3 July 2018 / Accepted: 4 October 2018 / Published online: 2 November 2018

(c) The Author(s) 2018

\begin{abstract}
Background In gastroesophageal reflux disease (GERD), the frequency of heartburn symptoms and erosive esophagitis (EE) increases with age in children and adolescents. Proton pump inhibitor, dexlansoprazole, is approved for healing EE of all grades, maintenance of healed EE, relief of heartburn, and treatment of symptomatic non-erosive GERD in patients $\geq 12$ years. Aim To assess safety and efficacy of dexlansoprazole dual delayed-release capsule in healing of EE and maintenance of healed EE in adolescents.

Methods A multicenter, phase 2, 36-week study was conducted in 62 adolescents (12-17 years) with endoscopically confirmed EE. Patients received dexlansoprazole $60 \mathrm{mg}$ once daily (QD) during open-label healing phase. Those with confirmed healing at week 8 were randomized to dexlansoprazole $30 \mathrm{mg}$ QD or placebo during 16-week, double-blind maintenance phase, with subsequent treatment-free follow-up of $\geq 12$ weeks. Primary endpoints were treatment-emergent adverse events (TEAEs) in $\geq 5 \%$ of patients during treatment. Secondary endpoints included percentages of patients with healing of EE and with maintenance of healed EE.

Results $88 \%$ of patients achieved EE healing, and $61.3 \%$ reported a TEAE [headache (12.9\%), oropharyngeal pain (8.1\%), diarrhea (6.5\%), and nasopharyngitis (6.5\%)]. During maintenance phase, healing was maintained in $82 \%$ and $58 \%$ of dexlansoprazole and placebo groups, respectively. $72.0 \%$ of dexlansoprazole-treated patients reported TEAEs, which included headache (24.0\%), abdominal pain (12.0\%), nasopharyngitis (12.0\%), pharyngitis (12.0\%), sinusitis (12.0\%), bronchitis (8.0\%), upper respiratory tract infection (8.0\%), and insomnia (8.0\%); 61.5\% experienced a TEAE with placebo.
\end{abstract}

Conclusions Dexlansoprazole is safe and efficacious for healing EE and maintenance of healed EE in adolescents.

Keywords Gastroesophageal reflux disease $\cdot$ Dexlansoprazole $\cdot$ Child $\cdot$ Esophagitis

Electronic supplementary material The online version of this article (https://doi.org/10.1007/s10620-018-5325-8) contains supplementary material, which is available to authorized users.

David Gremse

dgremse@health.southalabama.edu

1 Department of Pediatrics, University of South Alabama, 1504 Springhill Avenue, Rm 5309, Mobile, AL 36604, USA

2 Children's Center for Digestive Healthcare, Atlanta, GA, USA

3 Takeda Development Center Americas, Inc, Deerfield, IL, USA

4 Pediatric Department, State Hospital in Rzeszów, Medical College, University of Rzeszów, Rzeszów, Poland

\section{Introduction}

Gastroesophageal reflux occurs naturally in healthy infants, children, and adults without troublesome consequences [1]. Gastroesophageal reflux disease (GERD) is characterized by reflux of gastric contents that causes persistent symptoms such as heartburn, cough, epigastric pain, vomiting, and regurgitation. Troublesome symptoms associated with GERD are perceived by both the patient (over 8 years of age) and the patient's caretaker [2]. GERD has been proposed to exist as 5 distinct presentations: functional heartburn, hypersensitive esophagus, non-erosive GERD, erosive esophagitis (EE), and Barrett's esophagus. These phenotypes are clinically distinct rather than continuous, despite the similarity of symptoms among them [3]. Further, GERD symptoms in isolation cannot reliably predict $\mathrm{EE}$, and symptom severity does not correlate with the degree of mucosal injury. Since 
GERD symptoms cannot predict endoscopic findings, an EE diagnosis requires visual evidence of breaks in the esophageal mucosa above the gastroesophageal junction $[4,5]$.

GERD evolves over time in children and adolescents, with frequency of heartburn symptoms and prevalence of EE increasing with age. Although evidence is limited, one study reported the incidence of endoscopically confirmed EE as $10.5 \%$ in 12 -year-olds with GERD and $19.5 \%$ in 17 -yearolds. The individual symptom prevalence of heartburn in the general pediatric population was $1.8 \%$ in 3 - to 9 -yearolds, $3.5 \%$ in 10 - to 17 -year-olds, and $22 \%$ in over 18 -yearolds [6], while a survey of 615 children aged 10-17 years reported the prevalence of at least weekly heartburn to be 5-8\% [7, 8]. Prevalence rates of EE are higher in pediatric patients with underlying disorders such as neurologic impairment or repaired esophageal atresia; thus, children with persistent GERD symptoms, as well as GERD-promoting underlying conditions, are candidates for empiric proton pump inhibitor (PPI) treatment $[1,2]$.

Extensive evidence suggests that short-term (e.g., 8 weeks) treatment with PPIs such as omeprazole, esomeprazole, lansoprazole, rabeprazole, and pantoprazole is efficacious for healing EE and improving symptoms in children aged 1-17 years [9-15]. Clinical practice guidelines recommend PPIs as first-line therapy for up to 3 months for healing of EE in children, on the basis of expert opinion [1]. However, the need for maintenance PPI therapy in healed EE for pediatric patients without underlying conditions has been challenged, as relapse rates after healing vary from 2.2 to $25 \%[1,16,17]$. Higher relapse rates were observed in a greater proportion of patients with more severe grades of esophagitis or those with coexisting disorders that predispose to GERD $[1,17]$. These studies suggest that maintenance PPI therapy may be needed more in patients with higher grades of EE and/or underlying conditions [1, 17].

In 2009, the PPI dexlansoprazole (DEXILANT ${ }^{\circledR}$, Takeda Pharmaceuticals U.S.A., Inc.) capsule was approved at a 30-mg daily dose for adults to relieve heartburn, to maintain healed EE, and for relief of heartburn for up to 6 months, and to treat heartburn associated with symptomatic non-erosive GERD for 4 weeks. A daily dose of $60 \mathrm{mg}$ for up to 8 weeks was approved for the healing of EE [18]. In 2016, dexlansoprazole was approved for patients aged 12-17 years with GERD. Dexlansoprazole is an enantiomer of lansoprazole with a unique dual delayed-release formulation designed to extend the duration of drug exposure and resulting gastric acid suppression [18, 19]. After ingestion, an initial set of granules releases $25 \%$ of the drug dose on dissolution of the enteric coating when $\mathrm{pH}$ is $\geq 5.5$, which occurs in the proximal duodenum. The second set of granules releases the remaining $75 \%$ of the dexlansoprazole dose further along the gastrointestinal tract when $\mathrm{pH}$ is $\geq 6.75[19,20]$. In a study of adult patients, EE healing rates for a 60-mg daily dose of dexlansoprazole were superior to $30-\mathrm{mg}$ lansoprazole (85.3\% vs. $79.0 \% ; P=0.05)$, although another study reported no difference in EE healing (60 mg dexlansoprazole: $86.9 \%$; $30 \mathrm{mg}$ lansoprazole 84.6\%) [21]. After EE healing, dexlansoprazole has also shown efficacy at 30- and 60-mg oncedaily doses in maintaining healed EE for up to 6 months and in controlling heartburn for greater than $90 \%$ of treatment days [22]. A similar pharmacokinetic profile of once-daily dexlansoprazole has been observed in adolescents [23]. In the present trial, we investigated the safety, tolerability, and efficacy of dexlansoprazole for EE healing and maintenance of healed EE in adolescents with confirmed EE. These findings have practical implications for the treatment of GERD in pediatric and adolescent populations. Because GERD symptoms, and more importantly, GERD-related mucosal injury can carry over to adulthood [24], efforts to control or prevent further esophageal damage and improve quality of life are important for these young patients.

\section{Methods}

This international phase 2, multicenter, 36-week trial was designed to assess the safety and efficacy of dexlansoprazole treatment in adolescents (aged 12-17 years) with EE. The trial (EudraCT number: 2012-001681-15) was conducted from June 22, 2012, to November 10, 2014, and enrolled patients from 18 international sites, including 8 in the USA, 6 in Poland, 3 in Portugal, and 1 in Mexico (range per site 1-12). Study protocols were in accordance with the Declaration of Helsinki and the International Conference on Harmonisation (ICH) Harmonised Tripartite Guideline for Good Clinical Practice (GCP) [25, 26]. Before the initiation of study procedures, written consent was obtained from the parent or guardian, and assent was obtained from all adolescents.

This study protocol was in compliance with the Institutional Review Board regulations stated in Title 21 of the United States Code of Federal Regulations, Part 56, GCP regulations and guidelines, and all applicable local regulations.

\section{Study Participants}

A total of 237 adolescents were screened for the study and an accompanying trial that assessed adolescents with symptomatic non-erosive GERD (EudraCT number: 2012-00168072). The study aimed to enroll 60 patients with endoscopically confirmed EE and a history of GERD symptoms for at least 3 months before screening. Throughout the screening, treatment, and follow-up periods, patients documented the presence of heartburn symptoms in the morning and at night each day in an electronic diary (eDiary). Patients 
who reported heartburn on at least 3 of any 7 days during screening were scheduled for endoscopic confirmation of EE before receiving treatment. Based on the Los Angeles (LA) Classification Grading System, EE severity of grade A, B, $\mathrm{C}$, or D was required for study entry [27]. Endoscopies performed within a week before entering the study and 2 weeks before the beginning of the treatment phase were used if the procedures met minimum protocol requirements. Fasting serum gastrin levels were measured in all patients during the screening period, weeks 4 and 8 of the open-label phase, and weeks 16, 24, 32, and 36 of the maintenance phase.

Gastric mucosa biopsies (stomach antrum and fundus) were taken during the screening endoscopy to detect the presence of Helicobacter pylori, and positive patients were excluded from the study. Adolescents with evidence of disease, symptoms, or abnormal laboratory values that suggested a clinically significant, uncontrolled underlying condition (other than GERD or EE) that could potentially confound study results were also excluded; examples include any coexisting disease affecting the esophagus, Barrett's esophagus with dysplastic changes, eosinophilic esophagitis (EoE) or endoscopic findings suggestive of EoE, celiac disease, or positive tissue transglutaminase antibody test, active duodenal or gastric ulcers, human immunodeficiency virus
(HIV), cancer (except basal cell carcinoma) within 5 years of screening, or Zollinger-Ellison syndrome or another hypersecretory condition. Patients with hypersensitivity or allergies to dexlansoprazole, any component of dexlansoprazole or other PPI, or antacid containing $\mathrm{Mg}(\mathrm{OH})_{2}$ and/ or $\mathrm{Al}(\mathrm{OH})_{3}$ or simethicone were excluded, as well as any patients who had taken a PPI within 1 week of their screening visit, or who participated in another clinical study, and/ or received any investigational compound within 30 days before screening. In addition, patients who received or were planning to receive prohibited medications (e.g., histamine-2 receptor antagonists [H2RAs], non-site-supplied antacids or PPIs, nonsteroidal anti-inflammatory drugs, corticosteroids, misoprostol, anticoagulants, antiplatelet therapy, or drugs with significant anticholinergic effects) were also excluded from the study.

\section{Study Design}

The study consisted of 3 periods: screening (up to 21 days), treatment (8-week open-label healing phase, 16-week double-blind maintenance phase), and follow-up (3 months) (Fig. 1). Patients were instructed that lifestyle or behavior modifications for managing GERD symptoms should not be
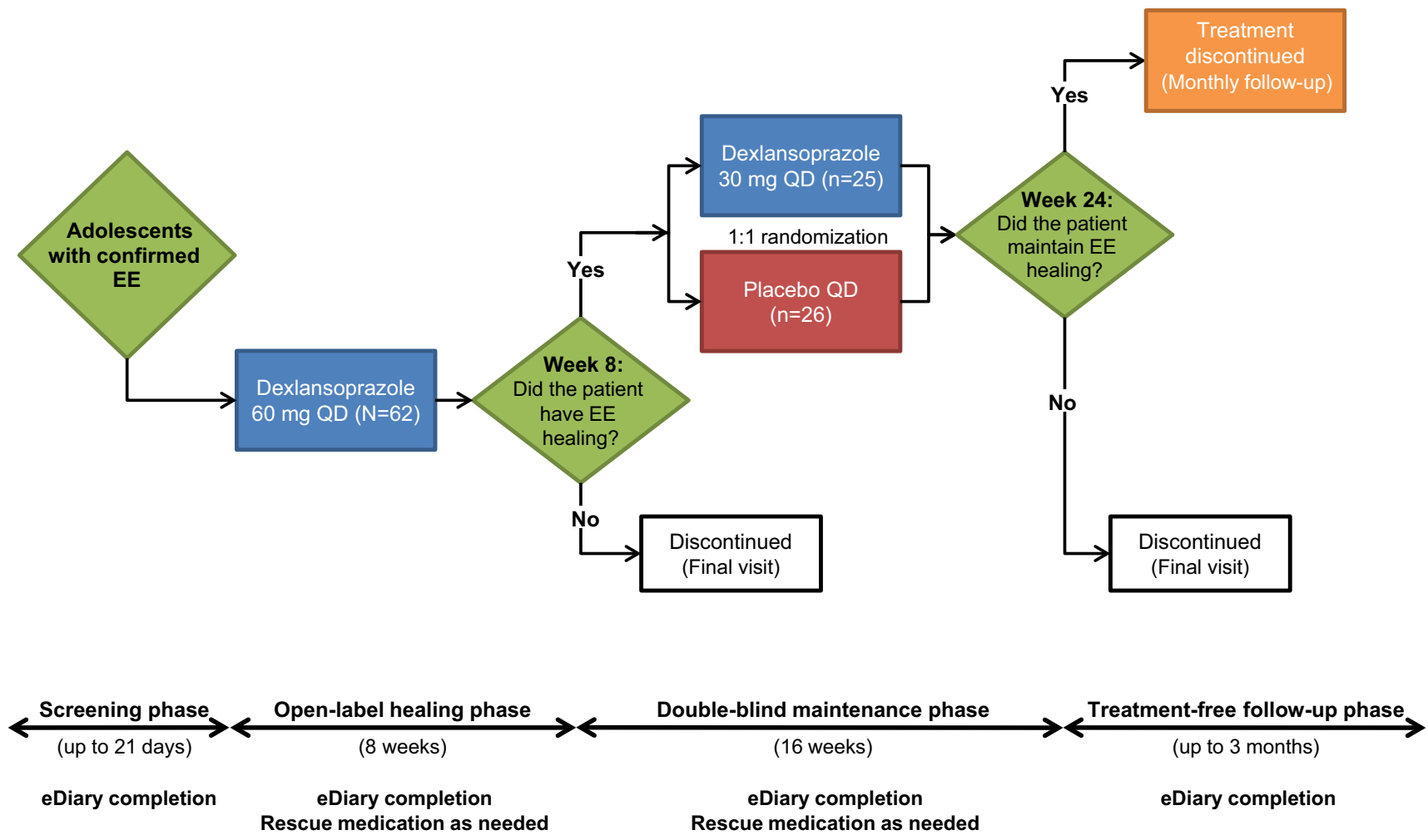

Fig. 1 Study design. The study included 4 periods: screening (up to 21 days), an open-label healing phase ( 8 weeks), a double-blind maintenance phase (16 weeks), and a posttreatment follow-up phase (up to 3 months). EE healing was assessed at week 8 and week 24 by endoscopy. $E E$ erosive esophagitis, $Q D$ once daily 
altered throughout the study. Adolescents with endoscopically confirmed EE were enrolled into the open-label healing phase and were given dexlansoprazole delayed-release 60-mg capsules administered orally once a day (QD) for 8 weeks (Fig. 1). At week 8 , an endoscopy was performed to assess healing of EE. Patients with confirmed healing were randomized (1:1) to receive daily administration of either a dexlansoprazole 30-mg capsule or placebo QD for the next 16 weeks to assess healed EE maintenance. Patients without healing at week 8 were discontinued from the study. Randomization during the maintenance phase of the study was scheduled using the interactive voice/web response system. Patients were re-assessed by endoscopy at week 24 after completion of the double-blind maintenance phase (Fig. 1). Patients who had relapsed EE at the end of the treatment phase were discontinued, and those with maintenance of healed EE returned to the clinic monthly during the followup period to assess recurrence of symptoms and relapse of EE. Study drug adherence was calculated by capsule count (total count of capsules taken/total number of days on study drug) separately for the healing and maintenance phases.

\section{Endpoints}

Primary endpoints were any treatment-emergent adverse events (TEAEs) observed in $\geq 5 \%$ of patients during the healing and maintenance phases. TEAEs were coded using the Medical Dictionary for Regulatory Activities (MedDRA; version 10.0 International Federation of Pharmaceutical Manufacturers and Associations, Geneva, Switzerland), and those that were determined to be related to the study drug by the investigator were termed treatment-related adverse events (TRAEs) [28]. Safety was assessed through adverse event assessments, physical examinations, monitoring of vital signs, routine laboratory evaluations, and standard 12-lead electrocardiograms. Secondary endpoints included the percentages of patients with healing of $\mathrm{EE}$ at week 8 and with maintenance of healed EE at week 24 (as assessed by endoscopy) and the percentage of days with neither daytime nor nighttime heartburn after treatment in the healing and maintenance phases (as assessed by eDiary). The rates of healing of EE at week 8 and maintenance of healed EE at week 24 were presented along with $95 \%$ exact confidence intervals (CIs).

Additional endpoints included the investigator-rated severity of GERD symptoms, and the severity of daytime and nighttime heartburn $(0=$ no heartburn, $1=$ did not hurt very much, $2=$ hurt some, and $3=$ hurt a lot), along with the percentage of days without nighttime heartburn and without rescue medication during the open-label and double-blind phases recorded via eDiary (Supplemental Table S1). Investigator-rated severity of GERD symptoms was evaluated at weeks 4, 8, 16, and 24. Efficacy was evaluated by endoscopy,
eDiary entry, and investigator assessment of GERD. Statistical analyses were performed using SAS version 9.2 software. Summary statistics (mean, median, number, or percentage) were calculated for variables such as baseline age, height, weight, and body mass index (BMI). During the doubleblind phase, the placebo and dexlansoprazole groups were compared with Fisher's exact test for the percentage of patients with maintenance of healed EE at week 24 and with Wilcoxon rank-sum tests for the percentage of days with neither daytime nor nighttime heartburn, without nighttime heartburn, and without daytime heartburn.

\section{Results}

\section{Patient Characteristics}

At the beginning of the study, the majority of patients had baseline EE grades of either A or B (Table 1). Two patients had baseline EE grades of $\mathrm{C}$ or $\mathrm{D}$ for healing phase. Constipation $(4.8 \%)$ and pneumonia $(4.8 \%)$ were the most commonly reported medical history; in addition, $4.8 \%$ of patients had previously undergone esophagogastroduodenoscopy. Among patients who entered the maintenance phase, all but one had baseline EE grades of either A or B; one patient in the placebo group had baseline EE of grade C. Other baseline characteristics between patients assigned to the dexlansoprazole and placebo treatment groups were similar (Table 1). Gastric biopsies were normal in 64.5\% of the patients, with chronic gastritis as the most common abnormal finding in the absence of $\mathrm{H}$. pylori (33.9\% of all patients).

Patient-reported heartburn frequency, severity, and rescue medication use measured during the 7 days prior to the openlabel healing phase and investigator-rated GERD symptom severity at baseline are shown in Table 2 . The frequency and severity of heartburn were greater during the day than at night during the week prior to initiating treatment (Table 2). Investigator-rated GERD symptom severity at baseline was mild or moderate in most patients. Heartburn and epigastric pain were the most commonly observed symptoms, occurring in $76 \%$ and $73 \%$ of patients, respectively (Table 2).

Of the 62 patients with EE initially selected to participate in the open-label healing phase (median study drug exposure, 56 days), 51 patients had documented healing at week 8 and entered the double-blind maintenance phase (Supplemental Figure S1). Four patients were unable to complete the healing phase, and 7 patients with unhealed EE were excluded from the maintenance phase (Supplemental Figure S1). During the maintenance phase, 22 and 24 patients were evaluable for maintenance of EE healing in the dexlansoprazole and placebo groups, respectively. A total of 38 patients completed this phase (median study drug exposure, 112 days 
Table 1 Baseline patient characteristics

\begin{tabular}{|c|c|c|c|}
\hline \multirow[t]{2}{*}{ Characteristic } & \multirow{2}{*}{$\begin{array}{l}\text { Open-label healing phase } \\
\text { Dexlansoprazole } 60 \mathrm{mg} \text { QD }(n=62)\end{array}$} & \multicolumn{2}{|c|}{ Double-blind maintenance phase } \\
\hline & & Placebo $(n=26)$ & $\begin{array}{l}\text { Dexlansopra- } \\
\text { zole } 30 \mathrm{mg} \text { QD } \\
(n=25)\end{array}$ \\
\hline \multicolumn{4}{|l|}{ Age } \\
\hline Years, mean \pm SD & $14.8 \pm 1.64$ & $14.8 \pm 1.75$ & $14.6 \pm 1.41$ \\
\hline $12-14$ years $[n(\%)]$ & $24(38.7)$ & $11(42.3)$ & $10(40.0)$ \\
\hline $15-17$ years $[n(\%)]$ & $38(61.3)$ & $15(57.7)$ & $15(60.0)$ \\
\hline Sex (male) $[n(\%)]$ & $38(61.3)$ & $16(61.5)$ & $14(56.0)$ \\
\hline \multicolumn{4}{|l|}{ Race } \\
\hline White $[n(\%)]$ & $61(98.4)$ & $25(96.2)$ & $25(100.0)$ \\
\hline Black/African American $[n(\%)]$ & $1(1.6)$ & $1(3.8)$ & 0 \\
\hline Weight $(\mathrm{kg})$, mean $\pm \mathrm{SD}$ & $61.86 \pm 17.06$ & $61.17 \pm 16.13$ & $62.63 \pm 16.67$ \\
\hline Height $(\mathrm{cm})$, mean $\pm \mathrm{SD}$ & $165.5 \pm 9.68$ & $166.5 \pm 10.60$ & $164.8 \pm 7.46$ \\
\hline $\operatorname{BMI}\left(\mathrm{kg} / \mathrm{m}^{2}\right)$ & $22.34 \pm 5.09$ & $21.89 \pm 4.80$ & $22.88 \pm 5.11$ \\
\hline \multicolumn{4}{|l|}{ Smoking classification $[n(\%)]$} \\
\hline Never smoked & $61(98.4)$ & $26(100.0)$ & $24(96.0)$ \\
\hline Current smoker & $1(1.6)$ & 0 & $1(4.0)$ \\
\hline \multicolumn{4}{|l|}{ H. pylori status $[n(\%)]$} \\
\hline Positive & 0 & 0 & 0 \\
\hline Negative & $61(98.4)$ & $26(100.0)$ & $24(96.0)$ \\
\hline Unknown & $1(1.6)$ & 0 & $1(4.0)$ \\
\hline \multicolumn{4}{|c|}{\left.${\text { Baseline EE } \text { grade }^{\mathrm{a}}(\text { LA classification }}^{\mathrm{b}}\right)[n(\%)]$} \\
\hline Grade A & $34(54.8)$ & $16(61.5)$ & $14(56.0)$ \\
\hline Grade B & $26(41.9)$ & $9(34.6)$ & $11(44.0)$ \\
\hline Grade C & $1(1.6)$ & $1(3.8)$ & 0 \\
\hline Grade D & $1(1.6)$ & 0 & 0 \\
\hline
\end{tabular}

$B M I$ body mass index, $E E$ erosive esophagitis, $L A$ Los Angeles, $Q D$ once daily, $S D$ standard deviation

${ }^{a}$ Baseline grades of EE severity were evaluated during the screening period

${ }^{\mathrm{b}}$ Grade A: One (or more) mucosal break $\leq 5 \mathrm{~mm}$ long that does not extend between the tops of two mucosal folds; Grade B: One (or more) mucosal break $>5 \mathrm{~mm}$ long that does not extend between the tops of two mucosal folds; Grade C: One (or more) mucosal break that is continuous between the tops of two or more mucosal folds but that involves $<75 \%$ of the circumference; Grade D: One (or more) mucosal break that involves $\geq 75 \%$ of the esophageal circumference

in both dexlansoprazole and placebo groups). Patients who maintained healing at the end of the 16-week double-blind phase discontinued study drug and were monitored for a follow-up period of up to 3 months (Supplemental Figure S1). Twenty-four patients completed the follow-up phase. Mean adherence rates of $95 \%$ and $96 \%$ were reported in the open-label healing phase and double-blind maintenance phase, respectively.

\section{Safety}

Most TEAEs across both phases of the study were considered mild or moderate in intensity (Table 3), and no deaths were reported. During the open-label healing phase, 38 patients $(61.3 \%)$ reported a total of 79 TEAEs (Table 3), and none were considered related to treatment. Headache (12.9\%) was the most commonly reported TEAE in the healing phase, followed by oropharyngeal pain (8.1\%), diarrhea (6.5\%), and nasopharyngitis (6.5\%). One patient experienced serious TEAEs, including substance abuse, during the healing phase and deliberate poisoning with diclofenac later during the follow-up period.

During the maintenance phase, 18 patients receiving dexlansoprazole $(72.0 \%)$ and 16 patients receiving placebo (61.5\%) reported a total of 45 and 46 TEAEs, respectively (Table 3). As in the healing phase, headache was the most commonly reported TEAE by both treatment groups in the maintenance phase, with $6(24.0 \%)$ dexlansoprazole-treated patients and $4(15.4 \%)$ placebo-exposed patients experiencing this event. In addition to headache, other TEAEs experienced by $\geq 5 \%$ of patients in the dexlansoprazole treatment group included abdominal pain, nasopharyngitis, pharyngitis, sinusitis, upper respiratory tract infection, bronchitis, and insomnia (Table 3). Three TEAEs during the maintenance 
Table 2 Disease characteristics in patients during the 7 days prior to starting the open-label healing phase

Patient-rated disease characteristic $(N=62)$

Heartburn (days), mean $\pm \mathrm{SD}^{\mathrm{a}}$

Daytime/nighttime heartburn

Nighttime heartburn

$4.8 \pm 2.07$

$3.0 \pm 2.24$

Daytime heartburn

$4.3 \pm 2.09$

Heartburn (severity), mean $\pm \mathrm{SD}^{\mathrm{a}, \mathrm{b}}$

Daytime/nighttime heartburn

$1.03 \pm 0.713$

Nighttime heartburn

$0.87 \pm 0.746$

Daytime heartburn

$1.21 \pm 0.743$

Rescue medication use (days), mean $\pm \mathrm{SD}^{\mathrm{a}}$

$1.6 \pm 1.67$

\begin{tabular}{|c|c|c|c|c|c|}
\hline \multirow[t]{2}{*}{ Symptom $[n(\%)]$} & \multicolumn{5}{|c|}{ Investigator-rated GERD symptom severity } \\
\hline & None & Mild & Moderate & Severe & Very severe \\
\hline Heartburn & $13(21.0)$ & $16(25.8)$ & $23(37.1)$ & $8(12.9)$ & 0 \\
\hline Acid regurgitation & $19(30.6)$ & $18(29.0)$ & $16(25.8)$ & $7(11.3)$ & $1(1.6)$ \\
\hline Dysphagia & $49(79.0)$ & $4(6.5)$ & $7(11.3)$ & 0 & 0 \\
\hline Belching & $22(35.5)$ & $16(25.8)$ & $14(22.6)$ & $7(11.3)$ & $1(1.6)$ \\
\hline Epigastric pain & $15(24.2)$ & $14(22.6)$ & $18(29.0)$ & $12(19.4)$ & $1(1.6)$ \\
\hline
\end{tabular}

eDiary electronic diary, GERD gastroesophageal reflux disease, $S D$ standard deviation

${ }^{a}$ Derived from eDiary data

${ }^{\mathrm{b}}$ Scale for severity: $0=$ none, $1=$ did not hurt very much, $2=$ hurt some, $3=$ hurt a lot

Table 3 Treatment-emergent adverse events

\begin{tabular}{|c|c|c|c|c|c|c|}
\hline \multirow[t]{3}{*}{$\mathrm{AE}$} & \multirow{2}{*}{\multicolumn{2}{|c|}{$\begin{array}{l}\text { Open-label healing phase } \\
\text { Dexlansoprazole } 60 \mathrm{mg} \text { QD } \\
(n=62)\end{array}$}} & \multicolumn{4}{|c|}{ Double-blind maintenance phase } \\
\hline & & & \multicolumn{2}{|c|}{ Placebo $(n=26)$} & \multicolumn{2}{|c|}{$\begin{array}{l}\text { Dexlansoprazole } 30 \mathrm{mg} \text { QD } \\
(n=25)\end{array}$} \\
\hline & Events, $n$ & Patients $[n(\%)]$ & Events $(n)$ & Patients, $[n(\%)]$ & Events $(n)$ & Patients, $[n(\%)]$ \\
\hline Any AE & 79 & $38(61.3)$ & 46 & $16(61.5)$ & 45 & $18(72.0)$ \\
\hline Mild & 62 & $29(46.8)$ & 35 & $8(30.8)$ & 37 & $11(44.0)$ \\
\hline Moderate & 16 & 8 (12.9) & 10 & 7 (26.9) & 7 & $6(24.0)$ \\
\hline Severe & 1 & $1(1.6)$ & 1 & $1(3.8)$ & 1 & $1(4.0)$ \\
\hline Any AE leading to discontinuation & 1 & $1(1.6)$ & 0 & 0 & 1 & $1(4.0)$ \\
\hline Any serious $\mathrm{AE}$ & 1 & $1(1.6)$ & 1 & $1(3.8)$ & 2 & $2(8.0)$ \\
\hline \multicolumn{7}{|c|}{ Common $\mathrm{AE}$ (reported by $\geq 5 \%$ of patients in any treatment group) $[n(\%)]$} \\
\hline Headache & $8(12.9)$ & & $4(15.4)$ & & $6(24.0)$ & \\
\hline Oropharyngeal pain & $5(8.1)$ & & $1(3.8)$ & & $1(4.0)$ & \\
\hline Diarrhea & $4(6.5)$ & & $2(7.7)$ & & 0 & \\
\hline Nasopharyngitis & $4(6.5)$ & & $4(15.4)$ & & $3(12.0)$ & \\
\hline Abdominal pain & $3(4.8)$ & & $3(11.5)$ & & $3(12.0)$ & \\
\hline Pharyngitis & $3(4.8)$ & & 0 & & $3(12.0)$ & \\
\hline Upper respiratory tract infection & $2(3.2)$ & & 0 & & $2(8.0)$ & \\
\hline Abdominal pain upper & $1(1.6)$ & & $2(7.7)$ & & $1(4.0)$ & \\
\hline Bronchitis & $1(1.6)$ & & $1(3.8)$ & & $2(8.0)$ & \\
\hline Insomnia & $1(1.6)$ & & 0 & & $2(8.0)$ & \\
\hline Sinusitis & $1(1.6)$ & & 0 & & $3(12.0)$ & \\
\hline Erosive esophagitis & 0 & & $2(7.7)$ & & $1(4.0)$ & \\
\hline Pyrexia & 0 & & $2(7.7)$ & & 0 & \\
\hline
\end{tabular}

$A E$ adverse events, $Q D$ once daily 
phase were considered serious and included a case each of convulsion (dexlansoprazole), recurrence of GERD (dexlansoprazole), and H1N1 influenza (placebo). Only the recurrence of GERD led to study discontinuation, and the event was considered by investigators to be related to the study drug. This patient had healing of grade A EE at week 8, but after hospitalization for stomach pain 10 weeks later, a follow-up endoscopy revealed reoccurrence of grade A EE. Two other TEAEs in the dexlansoprazole treatment group were considered to be treatment-related: abdominal pain (1 patient) and decreased appetite (1 patient). Twelve (67\%) and $5(36 \%)$ patients who had received dexlansoprazole maintenance treatment or placebo, respectively, experienced TEAEs during the treatment-free follow-up period (data not shown). No clinically concerning results were noted in the clinical laboratory, vital signs, ECG, or physical examination assessments.

Mean increase in serum gastrin was $64.1 \mathrm{pg} / \mathrm{mL}$ after 4 weeks of the open-label healing phase, and mean levels remained stable during the subsequent 4 weeks of this phase. During the maintenance phase, mean serum gastrin levels for subjects in the placebo group decreased to near-baseline levels by 8 weeks and remained at this level. In the $30-\mathrm{mg}$ dexlansoprazole group, mean serum gastrin values decreased by $7.4 \mathrm{pg} / \mathrm{mL}$ after 8 weeks and $19.0 \mathrm{pg} / \mathrm{mL}$ after 16 weeks. None of the patients in the dexlansoprazole group in the maintenance phase had elevated levels during the follow-up period.

\section{Efficacy}

\section{EE Healing Phase}

After 8 weeks of treatment with dexlansoprazole $60 \mathrm{mg}$ QD, $88 \%$ of evaluable patients in the open-label phase had healed EE (95\% CI: 76.7, 95.0) (Fig. 2a). In the intent-to-treat population, healed EE was observed in $82 \%$ (95\% CI: 70.5, 90.8) of patients enrolled in the 8-week open-label phase. Of the 7 patients whose EE persisted, 3 had EE that stayed at the same grade, 3 patients saw improvements (from grade B to $\mathrm{A}$ in 2 patients and from grade $\mathrm{D}$ to $\mathrm{B}$ in another), and 1 worsened (from grade B to C). Overall adherence among these patients was $85-100 \%$. Healing was achieved in $94 \%$ of patients with a baseline EE grade of A, while a healing rate of $83 \%$ was observed in patients with a baseline $\mathrm{EE}$ grade of B (Fig. 2a).

During the open-label healing phase, daytime heartburn was more common than nighttime heartburn; heartburn was absent for a median $73.9 \%$ of days and $85.4 \%$ of nights. Patients spent a median $65.8 \%$ of days during the 8 -week open-label healing phase with neither daytime nor nighttime heartburn. The median percentage of days that patients did
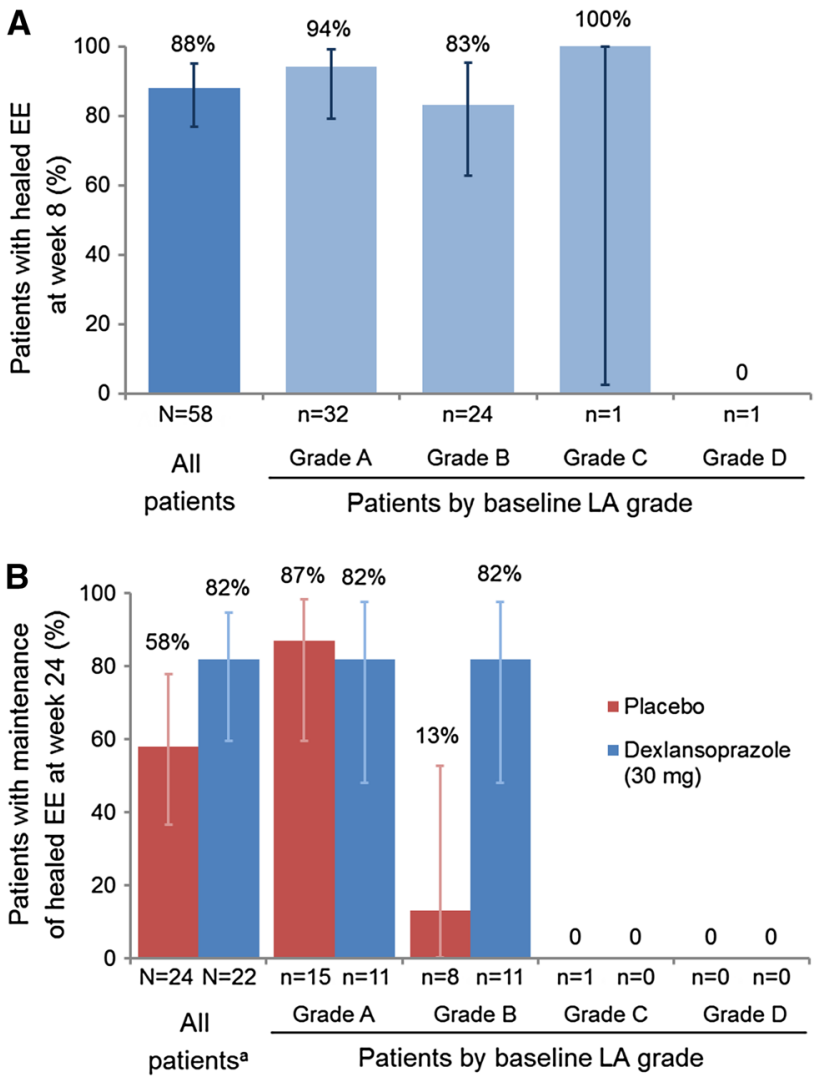

Fig. 2 Evaluation of EE healing and maintenance of healed EE. Percentages of patients with a healed $\mathrm{EE}$ at week 8 after administration of dexlansoprazole $60 \mathrm{mg}$ in the open-label phase and $\mathbf{b}$ maintenance of healed EE at week 24 during the double-blind phase. Error bars

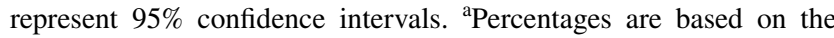
number of subjects that have results at week 24 . EE erosive esophagitis, $L A$ Los Angeles

not use rescue medication in the open-label healing phase was $96.6 \%$.

\section{Maintenance of Healed EE Phase}

Maintenance of healed EE at the end of the 16-week doubleblind phase was evaluable in 22 and 24 patients in dexlansoprazole $30 \mathrm{mg}$ QD and placebo groups, respectively. Maintenance of healed EE at the end of the 16-week double-blind maintenance phase was achieved in $82 \%$ (18/22 patients, 95\% CI: 59.7, 94.8; $P$ value vs. placebo 0.114$)$ and $58 \%$ (14/24 patients, $95 \%$ CI: $36.6,77.9)$ of evaluable patients receiving dexlansoprazole $30 \mathrm{mg}$ QD $(n=22)$ and placebo $(n=24)$, respectively (Fig. 2b). In the intent-to-treat population, maintenance of healed EE was observed in 72\% (95\% CI: 50.6, 87.9; $P$ value vs. placebo 0.249$)$ and 54\% (95\% CI: $33.4,73.4$ ) of patients randomized to dexlansoprazole $30 \mathrm{mg}$ QD and placebo, respectively. Four patients relapsed with dexlansoprazole $30 \mathrm{mg}$ QD: 3 patients returned to the same EE grade as they had at baseline, while 1 patient worsened 
from a baseline grade of B to grade C. The latter patient whose $\mathrm{EE}$ worsened had an adherence rate of $77.1 \%$, while adherence rates for the prior 3 patients ranged from 85.7 to $100 \%$.

Ten patients on placebo had a relapse of EE with 4 returning to their baseline EE grade of $B$ and 2 patients returning to their baseline EE grade of A. Four patients relapsed to a less severe EE grade than at baseline: 3 patients who had an $\mathrm{EE}$ of grade $\mathrm{B}$ at baseline relapsed to grade $\mathrm{A}$, and 1 patient who had an $\mathrm{EE}$ of grade $\mathrm{C}$ at baseline relapsed to grade $\mathrm{B}$.

Among patients with EE of grade $\mathrm{A}$ at baseline, similar rates of maintained healing were seen between those receiving dexlansoprazole $(82 \%)$ and those receiving placebo (87\%) (Fig. 2b). In contrast, a larger difference in maintenance rates between dexlansoprazole and placebo was observed among patients with EE of grade B (82\% with dexlansoprazole vs. $13 \%$ with placebo). One patient with $\mathrm{EE}$ of grade $\mathrm{C}$ at baseline who received placebo did not maintain healing.

Similar to results observed in the open-label healing phase, daytime heartburn was more common than nighttime heartburn in the maintenance phase. The median percentage of days without daytime heartburn was $89.7 \%$ in the dexlansoprazole group and $82.7 \%$ in the placebo group, while the median percentage of days without nighttime heartburn was $95.6 \%$ in the dexlansoprazole group and $90.3 \%$ in the placebo group. Heartburn (either daytime or nighttime) was absent for a median of $86.6 \%$ and $68.1 \%$ of days for the dexlansoprazole and placebo groups, respectively. The differences between the dexlansoprazole and placebo groups were not statistically significant.

\section{Treatment-Free Follow-up Phase}

Patients with healed EE at the end of the maintenance phase discontinued study drug before entering the follow-up phase. During the 3-month follow-up period, patients who had previously received dexlansoprazole or placebo had neither daytime nor nighttime heartburn for a median of $86.3 \%$ and $83.6 \%$ of days, respectively. No patients experienced a recurrence of symptoms that required an invasive procedure or treatment with a PPI or H2RA during the follow-up period; however, a study-drug-related reoccurrence of GERD was reported as an adverse event for 1 patient receiving dexlansoprazole during the maintenance phase. This patient was subsequently given omeprazole.

Median heartburn severity scores during daytime, nighttime, or both daytime and nighttime were no greater than 0.4 (on a scale of $0-3$ ) during all phases, indicating that most patients classified their heartburn as "not hurting very much." Patients in the dexlansoprazole and placebo groups did not use rescue medication for a median of $99.1 \%$ and $97.7 \%$ of days, respectively, during the double-blind phase.
During the follow-up phase, the need for rescue medication remained infrequent, with a median of $96.9 \%$ and $100.0 \%$ of days without rescue medication observed in the dexlansoprazole and placebo groups, respectively.

\section{Discussion}

The prevalence of EE increases progressively with age, and young people with chronic reflux disease may eventually develop esophageal mucosa complications similar to those in adults $[8,13,29]$. For pediatric patients in general, common reflux symptoms include regurgitation, cough, epigastric pain, and heartburn [2]. In adolescents, heartburn and regurgitation - which are the primary symptoms indicating GERD in adults-become more prevalent $[1,30]$. Currently, PPIs are the treatment of choice for relief of GERD symptoms and healing of EE in adults [30], and are recommended as first-line therapy in children with EE [1].

This study demonstrated that the safety and tolerability of dexlansoprazole in adolescents were consistent with the safety and tolerability profile observed in adults [31]. The majority of reported TEAEs for dexlansoprazole were mild in severity, with headache the most commonly reported $\mathrm{AE}$ by adolescent patients receiving either $30 \mathrm{mg}$ or $60 \mathrm{mg}$ of dexlansoprazole. Discontinuations were rare; only one patient discontinued the study because of an AE of GERD, suggesting that this patient may have experienced an inadequate response to dexlansoprazole.

In our study, dexlansoprazole resulted in an EE healing rate in adolescents of $88 \%$, comparable to that previously observed in adults (85\% and 87\%) [21]. A notable difference between the adolescent and adult studies, however, was that a greater proportion of adolescents (82\%) maintained EE healing with 16 weeks of continued dexlansoprazole treatment than that observed in adults (66\%) who received maintenance dexlansoprazole for 24 weeks. It is important to note that the patient population in the adult study had more severe EE (approximately $30 \%$ with grades $\mathrm{C}$ and D) than the adolescents in our study. Further, while the study durations were different, findings from a study by Boccia and colleagues suggested that children with uncomplicated GERD may not require maintenance therapy after EE healing [16]. Based on the findings of Boccia and colleagues [16] and to minimize placebo exposure, a shorter maintenance phase had been used in our adolescent study than that was used in the adult study. The numeric differences in EE healing rates between dexlansoprazole and placebo were notable but did not reach statistical significance; $58 \%$ of adolescent patients in the present study maintained $\mathrm{EE}$ healing with placebo, while in the adult study only $14 \%$ had remained healed with placebo treatment [22]. The maintenance of healed EE after placebo treatment in pediatric patients and not in adults may be a 
reflection on age-related differences in the natural history of GERD. Conversely, this observation could represent the less severe GERD phenotype in the pediatric patient at the time of diagnosis and treatment initiation. As suggested by the literature, adolescent EE may be an earlier phase of the adult disease [6-8, 32]. Consequently, once healed, adolescents may be less likely to relapse. In contrast, EE in adulthood may present with greater severity, as disease management may be further confounded by age-related increases in comorbid conditions and concomitant medication use that occurs with advancing age [33].

Our subgroup analysis of adolescents by baseline LA grade provides further support for the hypothesis that the high placebo rates for maintaining healed $\mathrm{EE}$ are driven by less severe disease. Adolescents with EE grade A at baseline who achieved complete healing with dexlansoprazole $60 \mathrm{mg}$ at week 8 appeared to maintain healed EE after dexlansoprazole was discontinued (i.e., after they were randomized to placebo). Adolescents with EE grade B appeared to benefit more from dexlansoprazole maintenance therapy; the difference in treatment was remarkably higher in those with $\mathrm{EE}$ grade B (82\% maintained healing with dexlansoprazole and only $13 \%$ with placebo) than in those with EE grade A ( $87 \%$ maintained healing with dexlansoprazole and $81 \%$ with placebo). These findings contradict the study by Boccia et al. who reported sustained EE healing in $97.8 \%$ of children with all grades of EE, regardless of whether they were on placebo or PPI treatment [16]. A limitation of our study is the lack of a significant proportion of patients with EE of grade C or $\mathrm{D}$, which could demonstrate that more severely affected adolescents respond better to maintenance therapy with dexlansoprazole. Another limitation of this study is the lack of independent blinded grading verification of the endoscopy readouts generated at the trial sites. Relying solely on readings by one endoscopist may have resulted in overestimation of EE occurrences at diagnosis, particularly low-grade EE. In turn, this observation could partially explain the high rate of healing and maintained healing in patients with $\mathrm{EE}$ grade A diagnosis, and the parity of results with placebo and dexlansoprazole in this subset of patients, since some of them may not have had actual EE.

In summary, this study supports the use of dexlansoprazole as a treatment option for EE: dexlansoprazole was generally safe and resulted in a numerically greater rate of maintenance of healed EE in adolescent patients compared with placebo. Overall, the results suggest that adolescents with mild EE (grade A) appeared more likely to maintain healed EE than those with higher-grade EE and that dexlansoprazole may provide greater maintenance benefit than placebo in patients with more severe disease.

Acknowledgments We are grateful to the study participants and their caretakers. Medical writing assistance was provided by Nafis Islam,
PharmD, and Bomina Yu, PhD, CMPP, of inVentiv Medical Communications and supported by Takeda Pharmaceuticals U.S.A., Inc.

Author's contribution All authors were involved in the design of the clinical study, acquisition of data, and analysis and interpretation of data for the manuscript. All authors were involved in the drafting and revising of the manuscript and have approved the final version.

Funding The clinical study was funded by Takeda Pharmaceuticals U.S.A., Inc.

\section{Compliance with ethical standards}

Conflict of interest Barbara Hunt and Maria Claudia Perez are employees of Takeda Development Center Americas, Inc., a wholly owned subsidiary of Takeda Pharmaceuticals U.S.A., Inc. Betsy Pilmer was employed by Takeda Development Center Americas, Inc., at the time of this study. David Gremse and Benjamin D. Gold were consultants for Takeda Pharmaceuticals of North America. Bartosz Korczowski has no relevant conflicts to disclose.

Availability of data and materials The datasets generated and/or analyzed during the current study are not publicly available owing to protection of rights and safety of patients involved in the investigation (Title 21 CFR, Part 50).

Informed consent The informed consent and assent forms described the planned and permitted uses, transfers, and disclosures of the subject's personal and personal health information for purposes of conducting the study, and further explained the nature of the study, its objectives, and potential risks and benefits. The informed consent and assent forms detailed the requirements of the participant and the fact that he or she was free to withdraw at any time without giving a reason and without prejudice to his or her further medical care. The date of informed consent/assent was recorded on the forms. The informed consent and assent forms were approved by both the institutional review board/independent ethics committees and the sponsor before use, and embodied the elements of informed consent and assent as described in the Declaration of Helsinki and the ICH Guidelines for GCP and were in accordance with all applicable laws and regulations.

Open Access This article is distributed under the terms of the Creative Commons Attribution-NonCommercial 4.0 International License (http://creativecommons.org/licenses/by-nc/4.0/), which permits any noncommercial use, distribution, and reproduction in any medium, provided you give appropriate credit to the original author(s) and the source, provide a link to the Creative Commons license, and indicate if changes were made.

\section{References}

1. Vandenplas Y, Rudolph CD, Di Lorenzo C, et al. Pediatric gastroesophageal reflux clinical practice guidelines: joint recommendations of the North American Society for Pediatric Gastroenterology, Hepatology, and Nutrition (NASPGHAN) and the European Society for Pediatric Gastroenterology, Hepatology, and Nutrition (ESPGHAN). J Pediatr Gastroenterol Nutr. 2009;49:498-547.

2. Sherman PM, Hassall E, Fagundes-Neto U, et al. A global, evidence-based consensus on the definition of gastroesophageal reflux disease in the pediatric population. Am J Gastroenterol. 2009;104:1278-1295. (quiz 1296). 
3. Nwokediuko SC. Current trends in the management of gastroesophageal reflux disease: a review. ISRN Gastroenterol. 2012;2012:391631.

4. Gupta SK, Hassall E, Chiu YL, Amer F, Heyman MB. Presenting symptoms of nonerosive and erosive esophagitis in pediatric patients. Dig Dis Sci. 2006;51:858-863. https://doi.org/10.1007/ s10620-006-9095-3

5. Guimaraes EV, Guerra PV, Penna FJ. Management of gastroesophageal reflux disease and erosive esophagitis in pediatric patients: focus on delayed-release esomeprazole. Ther Clin Risk Manag. 2010;6:531-537.

6. Cezard JP. Managing gastro-oesophageal reflux disease in children. Digestion. 2004;69:3-8.

7. Nelson SP, Chen EH, Syniar GM, Christoffel KK, Pediatric Practice Research Group. Prevalence of symptoms of gastroesophageal reflux during childhood: a pediatric practice-based survey. Arch Pediatr Adolesc Med. 2000;154:150-154.

8. Gilger MA, El-Serag HB, Gold BD, et al. Prevalence of endoscopic findings of erosive esophagitis in children: a populationbased study. J Pediatr Gastroenterol Nutr. 2008;47:141-146.

9. Gunasekaran TS, Hassall EG. Efficacy and safety of omeprazole for severe gastroesophageal reflux in children. $J$ Pediatr. 1993;123:148-154.

10. Hassall E, Israel D, Shepherd R, et al. Omeprazole for treatment of chronic erosive esophagitis in children: a multicenter study of efficacy, safety, tolerability and dose requirements. J Pediatr. 2000;137:800-807.

11. Tolia V, Ferry G, Gunasekaran T, Huang B, Keith R, Book L. Efficacy of lansoprazole in the treatment of gastroesophageal reflux disease in children. J Pediatr Gastroenterol Nutr. 2002;35:S308-S318.

12. Tolia V, Bishop PR, Tsou VM, et al. Multicenter, randomized, double-blind study comparing 10, 20 and $40 \mathrm{mg}$ pantoprazole in children (5-11 years) with symptomatic gastroesophageal reflux disease. J Pediatr Gastroenterol Nutr. 2006;42:384-391.

13. Gilger MA, Tolia V, Vandenplas Y, Youssef NN, Traxler B, Illueca M. Safety and tolerability of esomeprazole in children with gastroesophageal reflux disease. J Pediatr Gastroenterol Nutr. 2008;46:524-533.

14. Fiedorek S, Tolia V, Gold BD, et al. Efficacy and safety of lansoprazole in adolescents with symptomatic erosive and non-erosive gastroesophageal reflux disease. J Pediatr Gastroenterol Nutr. 2005;40:319-327.

15. Haddad I, Kierkus J, Tron E, et al. Maintenance of efficacy and safety of rabeprazole in children with endoscopically proven GERD. J Pediatr Gastroenterol Nutr. 2014;58:510-517.

16. Boccia G, Manguso F, Miele E, Buonavolonta R, Staiano A. Maintenance therapy for erosive esophagitis in children after healing by omeprazole: is it advisable? Am J Gastroenterol. 2007;102:1291-1297.

17. Hassall E, Shepherd R, Koletzko S, Radke M, Henderson C, Lundborg P. Long-term maintenance treatment with omeprazole in children with healed erosive oesophagitis: a prospective study. Aliment Pharmacol Ther. 2012;35:368-379.

18. Takeda. Dexilant (dexlansoprazole) [package insert]. Deerfield: Takeda Pharmaceuticals America, Inc.; 2016.
19. Vakily M, Zhang W, Wu J, Atkinson SN, Mulford D. Pharmacokinetics and pharmacodynamics of a known active PPI with a novel Dual Delayed Release technology, dexlansoprazole MR: a combined analysis of randomized controlled clinical trials. Curr Med Res Opin. 2009;25:627-638.

20. Frye JW, Peura DA. Managing gastroesophageal reflux diseasecomparative efficacy and outcomes of dexlansoprazole MR. Ther Clin Risk Manag. 2015;11:1649-1656.

21. Sharma P, Shaheen NJ, Perez MC, et al. Clinical trials: healing of erosive oesophagitis with dexlansoprazole MR, a proton pump inhibitor with a novel dual delayed-release formulation-results from two randomized controlled studies. Aliment Pharmacol Ther. 2009;29:731-741.

22. Metz DC, Howden CW, Perez MC, Larsen L, O'Neil J, Atkinson SN. Clinical trial: dexlansoprazole MR, a proton pump inhibitor with dual delayed-release technology, effectively controls symptoms and prevents relapse in patients with healed erosive oesophagitis. Aliment Pharmacol Ther. 2009;29:742-754.

23. Kukulka M, Wu J, Perez MC. Pharmacokinetics and safety of dexlansoprazole MR in adolescents with symptomatic GERD. $J$ Pediatr Gastroenterol Nutr. 2012;54:41-47.

24. El-Serag HB, Richardson P, Pilgrim P, Gilger MA. Determinants of gastroesophageal reflux disease in adults with a history of childhood gastroesophageal reflux disease. Clin Gastroenterol Hepatol. 2007;5:696-701.

25. World Medical Association. World Medical Association Declaration of Helsinki: ethical principles for medical research involving human subjects. JAMA. 2013;310:2191-2194.

26. International Conference on Harmonisation of technical requirements for registration of pharmaceuticals for human use. ICH harmonized tripartite guideline: guideline for Good Clinical Practice. J Postgrad Med. 2001;47:45-50.

27. Lundell LR, Dent J, Bennett JR, et al. Endoscopic assessment of oesophagitis: clinical and functional correlates and further validation of the Los Angeles classification. Gut. 1999;45:172-180.

28. Brown EG, Wood L, Wood S. The medical dictionary for regulatory activities (MedDRA). Drug Saf. 1999;20:109-117.

29. Gold BD, Freston JW. Gastroesophageal reflux in children: pathogenesis, prevalence, diagnosis, and role of proton pump inhibitors in treatment. Paediatr Drugs. 2002;4:673-685.

30. Katz PO, Gerson LB, Vela MF. Guidelines for the diagnosis and management of gastroesophageal reflux disease. Am J Gastroenterol. 2013;108:308-328. (quiz 329).

31. Peura DA, Metz DC, Dabholkar AH, Paris MM, Yu P, Atkinson SN. Safety profile of dexlansoprazole MR, a proton pump inhibitor with a novel dual delayed release formulation: global clinical trial experience. Aliment Pharmacol Ther. 2009;30:1010-1021.

32. Vandenplas Y, Hauser B. An updated review on gastro-esophageal reflux in pediatrics. Expert Rev Gastroenterol Hepatol. 2015;9:1511-1521.

33. Gold BD. Review article: epidemiology and management of gastro-oesophageal reflux in children. Aliment Pharmacol Ther. 2004;19:22-27. 